\title{
National service framework for coronary heart disease: audit of English hospitals
}

\author{
Michelle Rhodes, Christopher Newman, Susan Read
}

Percentages (numbers) of hospitals with audit standards (of national service framework for coronary heart disease) for delivery of thrombolysis in place at time questionnaire was received (July-December 2000)

\begin{tabular}{lcc} 
Audit standard & Door to needle time & Call to needle time \\
\hline In place & $86(108)$ & $39(49)$ \\
\hline$\leqslant 90$ minutes & NA & $5(6)$ \\
\hline$\leqslant 60$ minutes & NA & $29(36)$ \\
\hline$\leqslant 30$ minutes & $67(83)$ & NA \\
\hline$\leqslant 20$ minutes & $9(11)$ & NA \\
\hline$\leqslant 15$ minutes & $4(5)$ & NA \\
\hline
\end{tabular}

$\mathrm{NA}=$ not applicable.

The national service framework for coronary heart disease gives priority to reducing delays in the delivery of thrombolysis for acute myocardial infarction, aiming to achieve a "call to needle time" (from the initial call for help to treatment) of 60 minutes and a "door to needle time" (from arrival at the hospital to treatment) of 20 minutes or less by April 2003. ${ }^{1}$ We audited the delivery of thrombolysis in all acute hospitals in England.

\section{Methods and results}

We conducted a postal survey from July to December 2000 of all 201 acute hospitals in England that routinely admit patients with acute myocardial infarction. We identified hospitals from Binley's Directory of NHS Management and approached divisional or directorate managers by telephone. ${ }^{2}$ We then sent questionnaires to the appropriate person in coronary care units (or their equivalents), accident and emergency units, or assessment units, requesting information about audit standards at the time the questionnaire was received, audit data collected during the audit period of January to December 1999, and current practice of thrombolysis. We reminded participants by post or telephone after four and eight weeks.

More than $90 \%$ of the questionnaires were sent to senior staff in coronary care or emergency units; response rates of the two types of unit were similar (table A on bmj.com). One hundred and twenty five hospitals (62\%) responded. Limited information about non-responders was obtained during the final telephone reminder. Five per cent (10) said that they had returned a completed questionnaire, although the study coordinator had not received it, 4\% (7) had not collected the necessary data or found them too difficult to collate, and $2 \%$ (3) were too busy to participate.

In 2000, few hospitals had introduced standards that met the requirements of the national service framework (table). Data collection during the audit period was incomplete, particularly in relation to the call to needle time (see table B on bmj.com). Only 10\% (13) collected the mean and 3\% (4) the median call to needle time.

Of the 125 participating hospitals, 82\% (102) had introduced strategies to reduce delays in thrombolysis;
$49 \%$ (61) had been established before the audit period. Fifty per cent (62) collected audit data before and 75\% (94) after a strategy had been introduced. Data collected for audit purposes after the introduction of a strategy consisted of the door to needle time in $74 \%$ (93), percentage of patients receiving thrombolysis within 30 minutes of arrival in 59\% (74), and percentage receiving thrombolysis within 60 minutes of the call in 35\% (44) of hospitals.

Of the 97 strategies described, 63\% (61) entailed thrombolysis at entry to hospital; the remainder required transfer to coronary care units before treatment was started. Twenty three per cent (22) entailed a specific nursing intervention, mainly nurse led thrombolysis.

\section{Comment}

Audit data indicate shortfalls in relation to the delivery of thrombolysis, even in hospitals that had introduced measures to reduce delays in initial treatment. Deficiencies in the recording of the call to needle time were particularly evident. Available audit data are incomplete, and this hampers the objective assessment of any new intervention to reduce delays. The scale of the deficiencies identified by this audit highlights the additional investment in human resources and information technology that is required if the standards for audit and delivery embodied in this and other national service frameworks are to be achieved.

Contributors: MR undertook the study and analysed the data $\mathrm{CN}$ and SR supervised the study and the data analysis. The paper was written jointly by $\mathrm{MR}, \mathrm{CN}$, and $\mathrm{SR}$. MR is guarantor. Funding: None.

Competing interests: None declared.

Department of Health. National service framework for coronary heart disease modern standards and service models. London: $\mathrm{DoH}, 2000$.

2 NHS Confederation. Binley's directory of NHS management. Corringham: Beechwood House, 1999.

(Accepted 1 November 2001)

\section{Endpiece}

\section{Old age: contrasting attitudes}

The harvest is gathered in. At the age of 85 one has the right, perhaps the duty, of falling silent.

Camille Saint-Saens (1835-1921),

French composer of operas, symphonies, chamber music, and choral works

I am Joan Miró ... but I work every day and I want to die shouting mierda. (21 April 1978)

\section{Joan Miró (1893-1983) Spanish abstract painter}

Submitted by Fred Charatan, retired geriatric physician, Florida

\section{Department of \\ Nursing Studies, \\ St Martins College, \\ Carlisle CA1 2HH \\ Michelle Rhodes \\ senior lecturer \\ Clinical Sciences \\ Centre, University \\ of Sheffield, \\ Northern General \\ Hospital, Sheffield \\ S5 7AU \\ Christopher \\ Newman \\ senior lecturer \\ cardiology \\ School of Nursing \\ and Midwifery, \\ University of \\ Sheffield, Sheffield \\ S10 2HL \\ Susan Read \\ reader in nursing \\ research \\ Correspondence to: M Rhodes \\ m.rhodes@ucsm. \\ acuk}

BMJ 2002;324:709

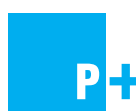

Extra tables appear on bmj.com 